\title{
La Vida Humana como Principio Interpretativo Radical en la Filosofía de Ortega y Gasset
}

\author{
Antonio Gutiérrez-Pozol
}

RESUMEN: En este artículo presentamos el concepto de vida humana como texto eterno en el pensamiento de Ortega y sus consecuencias para el problema de la interpretación. La filosofía de la razón vital de Ortega se fundamenta en el concepto de vida humana como realidad radical y principio interpretativo universal, y por esta razón se presenta desde el principio como una filosofía hermenéutica de la vida y no como una reducción hacia la conciencia trascendental. Esta hermenéutica se practica especialmente en el ámbito del arte. Pero para Ortega todo texto es hermenéutico y necesita por tanto la interpretación, porque ningún texto posee en sí mismo su verdad.

PALABRAS CLAVE: Ortega y Gasset, vida humana, interpretación, razón vital, texto.

\section{INTRODUCCIÓN}

Aunque la naturaleza hermenéutica de la filosofía de Ortega ha sido un aspecto incomprensiblemente poco destacado y atendido de su pensamiento ${ }^{2}$, en este trabajo sostenemos, primero, que la hermenéutica no es sólo y simplemente una dimensión más del pensamiento de Ortega, sino el núcleo de su filosofía de la razón vital e histórica, y segundo, que esa hermenéutica, apartándose de la conciencia trascendental de Husserl, se fundamenta sobre el concepto central de vida humana. Esto significa que la filosofía raciovitalista

\footnotetext{
${ }^{1}$ Doctor en Filosofía por la Universidad de Sevilla (España) y Profesor Titular de Universidad de la Facultad de Filosofía de la Universidad de Sevilla (España). Correo electrónico: agpozo@us.es

${ }^{2}$ Sobre esta dimensión de la filosofía de Ortega merecen ser destacados los estudios de FLÓREZ, R., 1987, p. 69-91; CEREZO, 1990, p. 307-344; CEREZO, 1993, p. 167-191; FLÓREZ, C., 1990, p. 439-448; MOLINUEVO, 2002, p. 120-125, 224-227; DOMINGO, 2005, p. 373-410; CASTELLÓ, 2009, passim.
} 
de Ortega, frente al trascendentalismo husserliano, es una hermenéutica de la vida humana. El carácter radical o fundamental del concepto de vida humana en el pensamiento de Ortega está ya anunciado en 1914, en el pasaje tal vez más significativo de toda su obra:

La vida es el texto eterno, la retama ardiendo al borde del camino donde Dios da sus voces. La cultura -arte, ciencia o política- es el comentario, es aquel modo de vida en que, refractándose ésta dentro de sí misma, adquiere pulimento y ordenación. (ORTEGA, Meditaciones del Quijote (1914), I, p. 788)

En este texto Ortega asume que la vida es el logos, la razón, el origen permanente e inagotable de todo significado, y que la cultura -de carácter entonces reflexivo- no puede consistir sino en interpretación o comentario de la propia vida. La cultura raciovitalista se presenta ya de entrada como hermenéutica de la vida y no como reducción hacia la conciencia trascendental. Con la evolución de su pensamiento, y especialmente a partir de la lectura de Sein und Zeit de Heidegger a finales de la década de los veinte, el concepto de vida humana al que se refiere Ortega como centro de su filosofía se decantará no como vida biológica, sino como vida biográfica, es decir, que la vida es "[...] lo que hacemos y nos pasa" (ORTEGA, ¿Qué es filosofía? (1929), VIII, p. 353). Ortega por tanto evolucionó desde un concepto visual, intelectualizado y estático de vida -comprendida entonces como perspectiva-, a una radicalización de la idea de vida humana en clave dinámica, entitativa y dialéctica, que desembocó en el concepto biográfico de vida (CEREZO, 1984, p. 303-315, 319-328). Sobre la base de la dinamización biográfica de la vida humana como realidad radical, la filosofía hermenéutica de Ortega adquirió su perfil definitivo a partir de la década de los treinta. El concepto maduro de Ortega de la vida humana como realidad radical es el fundamento filosófico de su hermenéutica de la vida como razón, o sea, como principio interpretativo radical. Por eso podemos considerar la filosofía hermenéutica de Ortega como una hermenéutica raciobiográfica, es decir, una hermenéutica en la que la vida (biográfica) es la razón o fundamento de sentido.

\footnotetext{
${ }^{3}$ Las citas de Ortega se refieren - salvo que se indique - a la edición de los ańos 2004-2010 en diez tomos de sus Obras Completas, especificando en romanos el tomo, y añadiendo el título y fecha de la obra sólo para los textos más relevantes respecto a nuestro trabajo.
} 


\section{LA VIDA HUMANA COMO PRINCIPIO RADICAL}

El concepto filosófico central de vida humana de Ortega se despliega en tres tesis, que representan a su vez tres dimensiones del carácter de principio radical que posee la vida, y que constituyen por tanto el núcleo de la filosofía madura de la razón vital. La primera tesis es el carácter metafísico radical de la vida humana concebida como fundamento o principio, la segunda es su consecuente estructura hermenéutica, y la última afirma la naturaleza narrativo/ dialéctica de la vida humana. Sobre estas tesis se asienta la fundamentalidad hermenéutica del concepto orteguiano de biografía raciovitalista. Dicho de otro modo: estas tres tesis son la base del concepto de vida humana como principio interpretativo radical. No es posible por tanto comprender adecuadamente la hermenéutica raciobiográfica sin desarrollar esos tres principios raciovitalistas. El primer principio de la filosofía raciovitalista afirma que la vida humana, o sea, mi vida , es el fundamentum absolutum et inconcussum, es decir, "[...] el ámbito donde todo lo demás se da -donde lo hay o lo hallo” (ORTEGA, VIII, p. 642). Ortega subraya que "[...] vivir es el modo de ser radical: toda otra cosa y modo de ser lo encuentro en mi vida, dentro de ella, como detalle de ella y referido a ella" (ORTEGA, ¿Qué es filosofía?, VIII, p. 345). Lo que hay en suma es la vida humana - mi vida -, pues "[...] el resto de realidades tiene que aparecer de un modo u otro en la vida" (ORTEGA, Historia como sistema (1941), VI, p. 47). En clave cartesiana, pero liberándose del idealismo de la conciencia, Ortega sostiene que sólo "mi vida" es, y esto significa que es la realidad radical y que "[...] todas las demás cosas de que hablamos, distintas de esa primordial, son dudosas y secundarias y no poseen más firmeza que la que reciben de apoyarse en la realidad indubitable" (ORTEGA, ¿Qué es filosofía?, VIII, p. 360). Por eso el propio Ortega resume todo el significado - metafísico y, con la segunda tesis, hermenéutico - de su filosofía de la radicalidad de la vida humana con la fórmula "[...] cartesianismo de la vida y no de la cogitatio" (ORTEGA, Historia como sistema, VI, p. 79).

De esta primera tesis se desprende la segunda, que consiste en síntesis en el despliegue en clave hermenéutica de aquella radicalidad vital. Las cosas, todo en general, también las vidas de los otros, no tienen más realidad que la que tienen en mi vida. Como todo se da y es en mi vida, y como no tengo noticia de ninguna cosa del mundo sino a través de lo que de todo ello me

\footnotetext{
4 "La vida, escribe Ortega, lo es siempre de alguien" (VIII, p. 417), y ańade que “[...] la vida es sólo la mía, esto es, la de cada cual" (VIII, p. 417, 424). No hay por tanto vida humana en abstracto sino que siempre es la de alguien (ORTEGA, ¿Qué es filosofía?, VIII, p. 345).
} 
aparece en mi vida, pues todo depende de mi vida, su ser, el ser de todas las cosas es el que tienen en mi vida: "En ella (mi vida) todo lo demás es y es lo que sea para ella, lo que sea como vivido" (ORTEGA, ¿Qué es filosofía?, VIII, p. 345). "Toda realidad, escribe Ortega, tendrá que serlo primero en mi vida: su realidad primaria consistirá en lo que sea como vivida por mí” (VIII, p. 418). Ya que todo se da en la vida humana, nada puede entenderse sino desde ella misma. Este es el carácter hermenéutico radical de la vida humana, la cual, en tanto realidad radical, es el fundamento de sentido último a que hay que reducir toda otra realidad para poder entenderla: "La vida humana es la realidad primordial en que todas las demás se fundan y a la que, en uno u otro sentido, habrá que reducir todas las otras si se quiere conocer su esencia radical" (ORTEGA, VIII, p. 420). Las cosas son lo que son en la (mi) vida. La vida humana es tanto fenómeno metafísico (fundamento donde todo se da) como, y por ello mismo, fenómeno hermenéutico (fundamento en cuya virtud todo tiene sentido): la biografía es razón de todo logos, principio radical de interpretación. La metafísica raciovitalista de la vida como realidad radical acaba consumándose por tanto en una hermenéutica raciobiográfica, según la cual, la vida humana, la de cada cual, es la que da razón (razón vital) de todo ser, convirtiéndose por tanto en el horizonte último de comprensión. La tesis principal de esta hermenéutica podría establecerse así: comprender algo (acción, obra, significado, etc.) implica localizarlo en la vida en que tuvo su origen y verlo funcionando en ella, pues a fin de cuentas la vida humana es razón. Estas dos tesis están conectadas esencialmente, de manera que la vida humana puede ser principio hermenéutico, fundamento de sentido, principio de comprensión de todo ente, sólo porque la propia vida humana es realidad radical. La hermenéutica raciobiográfica de Ortega es consecuencia de su metafísica de la vida humana.

Dado el carácter de realidad radical de la vida humana, el saber biográfico representa entonces la verdadera consumación de la metafísica, la ciencia radical. Para Ortega la biografía como disciplina no es una mera descripción de los hechos o experiencias vitales, sino su comprensión: da razón de ellas, y puede hacerlo porque la propia vida es (se da) razón. Esto es lo que significa la razón vital o razón biográfica. El carácter hermenéutico de la biografía se debe en último término a la estructura hermenéutica de la propia vida. La vida humana se explica a sí misma, da razón de sí desde dentro. Este es su carácter hermenéutico: la vida es razón, principio interpretativo de ella misma, de las experiencias, obras, textos o significados que en ella se producen, de modo que sólo desde ella pueden ser entendidos. Así llegamos al tercero de los principios 
que sostienen la hermenéutica raciobiográfica. Toda vida humana -individual o colectiva- consiste en una serie dialéctica de experiencias, de manera que unos sucesos vitales son las causas de los siguientes, y por tanto los que los hacen comprensibles, su logos. Por esto puede afirmarse que la vida humana tiene sentido y es inteligible: posee razón, razón narrativa o histórica, pues la comprensión de un hecho (biográfico o histórico) nos obliga a narrar los hechos anteriores. Somos ahora lo que somos porque antes fuimos otra cosa determinada. La racionalidad de las cosas humanas consiste en suma para Ortega en una narración (ORTEGA, Historia como sistema, VI, p. 71). Sólo una vida así es biográfica, puede tener biografía. Esto significa además que la vida humana para Ortega tiene una estructura histórica, es decir, siempre viene de (un pasado) y va hacia (un futuro), nunca parte de cero (ORTEGA, IX, p. 577-578). Nuestras experiencias personales pasadas condicionan y dan razón de las presentes y futuras, pero a su vez todas nuestras experiencias están condicionadas por (vienen de) todas las experiencias previas de los seres humanos, y condicionan (van hacia) todas las futuras. La historicidad de la vida equivale a una memoria ontológica, que Ortega denomina "razón histórica". En 1923 Ortega había escrito que "[...] vida es peculiaridad, cambio, desarrollo; en una palabra: historia” (ORTEGA, III, p. 612). Doce años después, Ortega concluyó que "[...] la historia es la ciencia sistemática de la realidad radical que es mi vida" (ORTEGA, Historia como sistema, VI, p. 75). La contextura de esta vida es biográfico/histórica o narrativa de la vida implica que la razón hermenéutica que se desprende de la vida humana ha de ser también narrativa: "Para comprender algo humano, personal o colectivo, es preciso contar una historia. Este hombre, esta nación hace tal cosa y es así porque antes hizo tal otra y fue de tal modo. La vida sólo se vuelve algo transparente ante la razón histórica" (ORTEGA, Historia como sistema, p. 71). Por tanto, la tercera tesis, el principio narrativo/ dialéctico, lo que hace es desplegar la naturaleza metafísica de la vida y darle forma (narrativa) a su carácter hermenéutico. Debido a que la razón que la vida humana da de sí y de todo lo que se da en ella - de todo, puesto que la vida es la realidad radical - es una razón histórica o narrativa, la biografía poseerá la misma racionalidad narrativa de la razón histórica. La razón hermenéutica orteguiana es por tanto una racionalidad de naturaleza histórico/narrativa o dialéctica (CEREZO, 1990, p. 338; 1993, p. 187). Por esto, Regalado sostiene que la biografía es el núcleo de la razón histórica entendida como método de desvelamiento de la vida humana, y por tanto el fundamento hermenéutico de las ciencias humanas, lo que equivale a considerar la biografía como base de la hermenéutica (REGALADO, 1990, p. 209-211). 


\section{LA VIDA HUMANA COMO PRINCIPIO INTERPRETATIVO DEL ARTE}

Ortega despliega especialmente esta hermenéutica raciobiográfica en el campo del arte, y no simplemente como un elemento auxiliar de su comprensión del arte, sino constituyéndose en la verdadera estética de la razón vital. En los textos escritos entre 1943 y 1954 sobre Goya (ORTEGA, IX, p. 759-822) y Velázquez (ORTEGA, VI, p. 603-744, 896-930), Ortega expone contra Heidegger una hermenéutica raciobiográfica del arte que responde a la expresión definitiva de su filosofía de la razón vital, y que por ello es concebida como el verdadero y único método adecuado de acceso al fenómeno artístico. El hecho de que esa hermenéutica se fundamente sobre su metafísica raciovitalista es lo que permite a Ortega captar el fenómeno artístico en un nivel más radical y obtener así un concepto riguroso de arte, dando por supuesto, tal como hace Ortega, que el nivel metafísico más radical es el de la vida humana. Frente a la primacía del ser en el pensamiento de Heidegger, esa hermenéutica del arte representa para Ortega la consecuencia más lograda de su estética humanista y, en general, del humanismo de su filosofía raciovitalista. El "cartesianismo de la vida" que proclama la filosofía de la razón vital y que no significa otra cosa que la reducción del ser a asunto vital, doméstico o intrabiográfico, representa la consumación del humanismo metafísico que caracteriza esencialmente al pensamiento de Ortega. El humanismo o antropologismo de la modernidad es una metafísica y consiste, según Heidegger, en la "[...] voluntad de explicarlo todo a partir del hombre y como expresión del mismo", de manera que "[...] nada es conocido y comprendido hasta no ser aclarado antropológicamente" (HEIDEGGER, 1991, p. 209). Resulta fácil advertir que el pensamiento de Ortega es un humanismo en este sentido heideggeriano. De hecho, explicar el arte en términos humanos es lo que pretende la estética orteguiana al desplegarse como hermenéutica raciobiográfica.

El arte para Ortega es esencialmente "cosa humana", un asunto humano, algo que hacen los hombres, y no el desvelamiento o puesta en obra del ser. Nada más lejos de esta humanización moderna del arte que la definición de Heidegger de la esencia del arte como el ponerse en obra de la verdad de lo ente (sich-ins-Werk-Setzen der Wahrheit des Seienden) (HEIDEGGER, 1977, p. 25, 58). El arte consiste en "[...] un llegar a ser y acontecer de la verdad", del ser (HEIDEGGER, 1977, p. 59). Heidegger deshumaniza radicalmente la esencia del arte, la aparta del ámbito intrahumano. En el "ponerse en obra de la verdad" en que consiste esencialmente el arte, la verdad misma, el ser, es sin duda objeto de ese poner, pero sobre todo es el sujeto. La deshumanización 
del arte efectuada por Heidegger no sólo se refiere entonces al hecho de que en la obra no se expresen -como objeto - las vivencias humanas, sino a que en ella se manifiesta - como sujeto - el propio ser y no el hombre. La obra de arte por tanto no sólo obra el ser: ella misma es obra (creación) del ser. El ser - a verdad - es acontecimiento, es poniéndose en obra. Según Heidegger, forma parte de la esencia de la verdad "una tendencia a la obra", o sea, "[...] tener que establecerse en lo ente” (HEIDEGGER, 1977, p. 25, 50). No hay más ser (verdad) que el que se pone en obra, y la obra de arte es un acontecimiento del ser. El arte para Heidegger no es expresión de las vivencias del ser humano, sino el "ponerse en obra de la verdad misma".

Para Ortega, en cambio, "[...] la pintura es una cosa que unos hombres hacen mientras otros la miran, copian, critican, teorizan, etc.", o sea, consiste en "un vasto repertorio de acciones humanas", de manera que "[...] fuera y aparte de éstas, la pintura no es nada” (ORTEGA, Velázquez (1950), VI, p. 609). Evidentemente, estas afirmaciones valen tanto para la pintura como para el arte en general. En suma, el arte es "mero ajetreo humano" (ORTEGA, Velázquez, p. 609). Por supuesto, para Ortega el arte tiene también una voluntad de verdad: como el resto de dimensiones de la cultura, posee una "misión esclarecedora" del texto eterno de la vida (ORTEGA, Meditaciones del Quijote, I, p. 789). Ahora bien, en clave humanista/metafísica, es una voluntad humana de verdad, o sea, algo que hace el ser humano. Una obra de arte, un cuadro en concreto, podrá desvelar la verdad de un ente, pero consiste según Ortega en "[...] unas pinceladas dadas por una mano con una intención" (ORTEGA, Preludio a un Goya (1946), IX, p. 766). Una obra de arte se reduce a una serie de acciones humanas, a un acontecimiento biográfico, no a un acontecimiento del ser. Para Heidegger sólo como acontecimiento del ser puede ser entendida una obra de arte. Frente a esta hermenéutica ontológica de Heidegger, Ortega expone una hermenéutica humanista raciobiográfica del arte. Si cada trozo de un cuadro o de una obra de arte en general, como sostiene Ortega, "[...] es testimonio perdurable de una resolución tomada por el artista” (ORTEGA, Velázquez, VI, p. 612); si "en el hecho de ser pintor desemboca la vida entera de un hombre y, por tanto, la de toda su época. Y todo ello vive en cada pincelada", entonces "[...] ver bien un cuadro es verlo haciéndose [...] dotarlo de reviviscencia actualizándonos la biografía del autor. Sólo así llegamos a la auténtica realidad del cuadro" (ORTEGA, Velázquez, p. 616). Ni los detalles particulares de una obra de arte, ni la obra misma en su conjunto, afirma Ortega, se pueden entender "[...] sin hacer intervenir [...] la biografía entera" 
del artista (ORTEGA, Velázquez, p. 617). Dado que según la hermenéutica raciobiográfica de Ortega nada es comprensible si no es reducible a producto de una vida humana, si pretendemos entender un fenómeno artístico tenemos que entender la vida donde se originó. La hermenéutica orteguiana del arte mantiene que la vida del artista es el principio radical de interpretación de su arte, "[...] la gramática y el diccionario que nos permitiría, si la conociésemos, leer inequívocamente su obra” (ORTEGA, Preludio a un Goya, IX, p. 767).

\section{ARTE E INTERPRETACIÓN}

En el arte, según Ortega, el ser humano conoce, expresa y comunica. "La obra es entonces, escribe, formalmente un aparato de significar [...] En ella lo que hacemos lo hacemos para que otro venga en noticia de algo que hay en nuestra intimidad y que solo puede ser comunicado al través de una realidad corporal" (ORTEGA, Velázquez, VI, p. 610). Para la filosofía humanista de la razón vital, el fundamento (antropológico, por supuesto) del arte es que el ser humano es constitutivamente "[...] el Dicente, esto es, el que tiene cosas que decir" (ORTEGA, El hombre y la gente (1949/50), X, p. 305). El ser humano está dotado de la facultad semántica, o sea, de la capacidad de crear signos para expresar y comunicar lo que hay en su interior, lo que conoce. Sin duda, la actividad semántica más conocida es el lenguaje, pero éste es sólo una forma de expresión y comunicación. El ser humano no tiene suficiente con el lenguaje para satisfacer su necesidad de decir, su ansia de expresar. Hay cosas que no se pueden decir con el lenguaje ya dado. Entonces nace el arte, "[...] porque se quiere expresar precisamente ciertas cosas que el lenguaje, por sí, no podrá nunca decir” (ORTEGA, Velázquez, VI, p. 611). El arte entonces, añade Ortega, "[...] comienza su faena comunicativa donde el lenguaje concluye" (Id.), y esto incluye a la poesía, que "no es lenguaje" sino "[...] una nueva potencia de la palabra irreductible a lo que esta propiamente es” (ORTEGA, 1983, vol. VIII, p. 491 nota). Por tanto el arte es, al tiempo, tanto una forma de expresión y comunicación como de conocimiento, esto es, un modo de la verdad.

Según Ortega, el lenguaje no sólo es una forma de comunicación de nuestros conocimientos, sino que es el "[...] instrumento más perfecto que para comunicarse tienen los hombres", y "[...] su perfección [...] consiste en que al 'decir' no sólo comunicamos algo, sino que lo patentizamos, lo declaramos de modo que no sea cuestionable qué es eso que queremos 
comunicar" (ORTEGA, Velázquez, VI, p. 610). Ortega considera que “[...] el lenguaje va movido por la aspiración a que su actividad comunicativa no necesite, a su vez, interpretación” (ORTEGA, Velázquez, p. 610). Puede luego lograrlo o no, pero lo esencial es que la palabra está animada por una voluntad declarativa, o sea, por el "[...] ideal de entregar, sin más, su sentido" (ORTEGA, Velázquez, p. 610). Si decimos, escribe Ortega, que "la nieve es blanca" damos a entender que posee realmente ese color blanco, pero, añade, cuando en un poema se dice que "la mejilla de una muchacha es como una rosa" o que "el ciprés es como el espectro de una llama muerta" no se da a entender que realmente eso sea así, sino que lo es metafóricamente (ORTEGA, IX, p. 838-839; ORTEGA, I, p. 673). Así son el conocimiento y la expresión artísticas, metafóricos o enigmáticos y no declarativos, y esto significa que no declaran ni patentizan lo que dicen, no lo ponen en claro sino que lo dicen enigmáticamente. Por eso están necesitados de interpretación. El arte, escribe Ortega refiriéndose en particular a la pintura, "[...] no es cuestión de ojos, sino de interpretación” (ORTEGA, Velázquez, VI, p. 611); o sea, no es sólo ni principalmente objeto estético, sino objeto de conocimiento interpretativo. El arte nos exige el esfuerzo de la interpretación, un esfuerzo interminable porque toda obra de arte surge para decir lo que por definición no se puede decir directa o declarativamente, y por eso mismo no puede interpretarse plenamente, o sea, no puede traducirse a un decir declarativo que pudiera ponerse en su lugar.

\section{LA VITALIDAD DEL SIGNIFICADO Y LA VIDA COMO PRINCIPIO INTERPRETATIVO UNIVERSAL}

Pero para Ortega no sólo el decir metafórico del arte exige interpretación. Hay una necesidad más profunda de interpretación, debida a la naturaleza (hermenéutica) misma del decir en general. Todo decir, aunque diga patente y declarativamente su sentido, es hermenéutico, o sea, no es un decir al estilo cartesiano claro y distinto, cerrado en sí y comprensible desde él mismo. Por eso para Ortega todo decir necesita la interpretación. El carácter hermenéutico del decir consiste en que para Ortega, y contra el idealismo semántico dominante desde Platón, no hay un significado puro y absoluto, sub specie aeterni, sino sólo significados vitales, abiertos, circunstanciales. Frente al significado ya establecido, el significado abstracto del diccionario, Ortega afirma que el verdadero significado es el que tienen las palabras, y en general todo texto, en la vida: "Las palabras no son palabras, sino cuando son 
dichas por alguien. Sólo así, funcionando como concreta acción, como acción viviente de un ser humano sobre otro ser humano, tienen realidad verbal", de modo que "[...] la realidad 'palabra' es inseparable de quien la dice, de a quien va dicha y de la situación en que esto acontece. Todo lo que no sea tomar así la palabra es convertirla en una abstracción" (ORTEGA, El hombre y la gente (1949/50), X, p. 299). Contra el abstracto idealismo semántico, el significado es vital, circunstancial: a todas las palabras les sucede, escribe Ortega, que "[...] su significación auténtica es siempre ocasional, que su sentido preciso depende de la situación o circunstancia en que sean dichas" (ORTEGA, El hombre y la gente, X, p. 302).

Un significado que es función vital es un significado abierto (a la circunstancia), y por tanto no limitado (cerrado) a un determinado sentido definido en abstracto en el diccionario. A diferencia del significado captable en la proposición, un significado semejante (raciovitalista) es hermenéutico, necesitado esencialmente de interpretación. En definitiva, lo hermenéutico se opone a la voluntad platónica y cartesiana que domina especialmente la modernidad y que cree que existen significados absolutos y abstractos, clausurables en la proposición. Este ideal lógico antihermenéutico se debe a la desconexión de entrada entre lo racional y lo vital. En la misma dirección hermenéutica que Ortega, Gadamer confirma que este idealismo lógico se centra en la pura proposición (Aussage), pero que realmente "lo que entendemos por enunciado nunca está exento de motivaciones”, de modo que “[...] el enunciado puro es una ficción” (GADAMER, 1986a, p. 194-195). Para Gadamer, "[...] no hay ningún enunciado que se pueda comprender únicamente por el contenido (Inhalt) que propone", pues “[...] todo enunciado tiene presupuestos (Voraussetzungen) que no enuncia (aussagt)" y "sólo quien piensa también estos presupuestos puede sopesar realmente la verdad de un enunciado" (GADAMER, 1986b, p. 52). Contra el idealismo, el espíritu de la hermenéutica afirma en palabras de Gadamer que "[...] nunca un enunciado posee su pleno sentido en sí mismo" (GADAMER, 1986a, p. 195). Pero la cultura científica moderna ha primado la proposición (apophansis), olvidando lo que está más allá de lo lingüístico, lo no dicho y tal vez no expresable (GADAMER, 1993, p. 358). Este espíritu hermenéutico es el que se despliega en el pensamiento de Ortega cuando niega el significado abstracto del diccionario y lo abre a la experiencia vital, al mundo de la vida. La recusación hermenéutica del idealismo semántico está ya planteada implícitamente en la tesis central del pensamiento raciovitalista, en la afirmación de la vida como texto eterno, como origen de todo significado. Pero afirmar la vida como texto 
eterno implica que la vida será también principio de interpretación de todo significado, o sea, principio interpretativo universal.

\section{DEFICIENCIA Y EXUBERANCIA DEL DECIR RACIOVITALISTA}

Esta doble dimensión de la vida humana es la base de lo que Ortega llama sus "Principios de una nueva Filología" (ORTEGA, Velázquez, VI, p. 612; ORTEGA, IX, p. 729), o sea, las dos tesis básicas en que se despliega su concepto de la vida como principio interpretativo. Estas dos tesis son las consecuencias de un decir fundado en la vida y la circunstancia. A pesar de que el arte surge para decir lo que no se puede decir directamente con el lenguaje, la necesidad de decir que constituye al ser humano tampoco se satisface con el arte porque es inagotable. Por eso, escribe Ortega, "[...] todo decir es deficiente, dice menos de lo quiere” (ORTEGA, Velázquez, VI, p. 612; ORTEGA, IX, p. 729). Esta es la primera tesis, el primer principio de la hermenéutica orteguiana. "Lo que quiere decir", su voluntad de decir, es siempre más de lo que dice, y por eso es indecible. Un decir así es hermenéutico, ya que no es reducible a fórmula discursiva. El fundamento de esta tesis reside en la riqueza de la necesidad expresiva de la vida, que siempre supera las posibilidades del instrumento lingüístico. Toda voluntad de decir tiene que realizarse en una determinada lengua, pero ésta siempre le impone unas restricciones que le impiden mostrar toda su pregnancia de significado. Por eso, cada lengua abre una serie de posibilidades al decir, de manera que entonces, escribe Ortega, "[...] cada lengua es una ecuación diferente de manifestaciones y silencios. Cada pueblo calla unas cosas para poder decir otras. Porque todo sería indecible" (ORTEGA, El hombre y la gente, X, p. 306307; ORTEGA, Miseria y esplendor de la traducción (1937), V, p. 717). Todo es indecible porque la abundancia de sentido del texto vital desborda siempre las estructuras categoriales en las que intentamos sistematizarlo: "La vida es un fluido indócil que no se deja retener, apresar, salvar" (ORTEGA, II, p. 627). El mundo últimamente sensible, el nivel de la pura afección que representa la efectividad del vivir, es en último término refractario al proyecto de total categorización simbólica. Esto es lo que significa para Ortega que la vida sea texto eterno, que "[...] la realidad es un 'continuo de diversidad' inagotable" que sorprende todos nuestros sistemas simbólicos de fijación (ORTEGA, Miseria y esplendor de la traducción, V, p. 719). El mundo de la vida es la fuente de todo significado, el texto que hay que leer para obtener logos, pero, al tiempo, es un texto que rebasa todo cuanto decimos de él, que supera todos 
los significados que, al leerlo, extraemos y decantamos en fórmulas. Es un texto antepredicativo que trasvasamos mediante la reflexión en palabras y conceptos, pero nunca del todo. El texto vital nunca podrá ser igualado por la reflexión, que queda entonces condenada a un trabajo infinito. La filosofía de la razón vital se constituye sobre esta tensión constante entre la riqueza salvaje de sentido que surge de la vida y el proyecto de la reflexión de domesticarla y objetivarla mediante conceptos: "Entre la idea y la cosa hay siempre una absoluta distancia. Lo real rebosa siempre del concepto que intenta contenerlo" (ORTEGA, III, p. 867). Esta inadecuación esencial entre la experiencia vital y su categorización conceptual es lo que está en la base del pensamiento de Ortega. Todo decir apunta siempre a algo más que quiere decir y no puede.

El segundo principio de la hermenéutica orteguiana afirma que "[...] todo decir es exuberante, da a entender más de lo que se propone" (ORTEGA, Velázquez, VI, p. 612; ORTEGA, IX, p. 729). Este principio sostiene que todo lo dicho no se limita a lo que dice expresamente, sino que muestra o da a entender más. Si el primer principio nos enseńa, por una parte, que la voluntad de decir rebasa lo dicho, aquí Ortega enseña, por otra parte, que también lo dicho a su vez supera a la voluntad de decir en tanto que muestra más de lo que quería decir. Todo lo dicho implica más de lo que dice, y ese más (no dicho) queda mostrado. Esto sólo es posible porque todo decir se levanta sobre algo supuesto, un fondo inexpreso, implícito. Este fondo se refiere en primer lugar a otros textos más amplios de los cuales forma parte cualquier decir, pero ya que todo decir -como función vital que es- es un fragmento de una vida humana, entonces implica latentemente todo lo que esa forma de vida a la que pertenece da por supuesto. Este es el fondo que subyace a todo texto. Esto significa que el decir pertenece a una vida y que abstraído de ella es ininteligible. Además, toda vida humana está sostenida sobre un suelo de pre-juicios o supuestos históricos y culturales, de manera que en todo decir está presente ese mundo histórico, como un supuesto, de forma latente, como algo no dicho. No hay un decir que no lleve consigo un contexto históricovital, que es en suma lo que le da sentido, de modo que sin él no podríamos entenderlo. En definitiva, Ortega escribe que

[...] todo texto se nos presenta por sí mismo como fragmento de un contexto. Pero texto y contexto, a su vez, suponen y hacen referencia a una situación en vista de la cual todo aquel decir surgió [...] La situación real desde la que se habla o escribe es el contexto general de toda expresión. El lenguaje actúa siempre referido a ella, la implica y reclama. (ORTEGA, VI, p. 147). 
Todo eso que se da por supuesto en una vida no es preciso decirlo, ya que es aquello con lo que se cuenta, aquello en lo que ya se está: "Todo decir expreso subdice o da por dichas muchas cosas que en el pensamiento actúan, que forman parte de su pensamiento" (ORTEGA, IX, p. 719). Pero está sub-dicho o sobrentendido en lo que se dice explícitamente, de modo que sin ese subsuelo inexpreso no sería entendible lo dicho expresamente. Los textos (obras) surgen en y por una determinada vida histórica, que por eso se convierte en su verdadera condición de inteligibilidad. La hermenéutica que plantea Ortega con este segundo principio consiste en referir el texto al fondo intelectual e histórico-vital donde surgió. Sólo así podrá volverse comprensible. Entonces, la hermenéutica raciobiográfica de Ortega es, en sus propias palabras, reviviscencia (ORTEGA, Velázquez, VI, p. 609): consiste en ver la obra (texto) in status nascendi, en ver nacer la obra a partir de la vida humana donde se originó. Para la hermenéutica orteguiana no hay comprensión sino reviviendo la vida integral que produjo la obra- o sea, la biografía del autor y su mundo histórico. Es una tarea de reconstrucción del contexto total donde vio la luz el texto en cuestión. En palabras de Goethe, Ortega afirma que "[...] quien quiera entender al poeta debe trasladarse a la tierra del poeta” (ORTEGA, VIII, p. 6).

Estos dos principios de la hermenéutica de Ortega enseñan el carácter hermenéutico del texto (decir), que consiste en que todo texto (todo decir) se trasciende a sí mismo, apunta a algo más de lo que él mismo explicita, de modo que la "proposición pura" explota abriéndose hacia sus márgenes. No hay enunciados que puedan ser comprendidos atendiendo exclusivamente a su contenido, a lo que él mismo enuncia declarativamente. La idealista proposición pura, que pretende poseer pleno sentido en sí misma, se deshace, rebasando sus límites en dirección a aquello que la trasciende y le da sentido. Todo decir es hermenéutico para Ortega porque ninguno enuncia plenamente su sentido en sí mismo, sino que, en vez de ello, cada decir apunta hacia su horizonte de sentido - sea su voluntad de decir o su mundo históricovital. Según los dos principios, que actúan conjuntamente, todo decir, por una parte, dice menos de lo que quiere, ya que apunta hacia una necesidad expresiva o voluntad de decir que siempre queda insatisfecha, pero, por otra parte, todo decir muestra también más de lo que quiere, ya que presupone como punto propio de partida un mundo histórico-vital. El querer decir del primer principio es necesariamente más de lo que se dice, y lo que se muestra o se da a entender del segundo principio también es siempre más de lo que se dice. Por tanto, "lo que se dice", lo que se enuncia declarativamente, es siempre 
menos de aquello hacia lo que apunta, es como la punta de un iceberg. De los dos principios se deduce que el decir está constituido por algo (un querer decir y lo mostrado) que lo trasciende, de manera que puede afirmarse que el decir siempre apela a más y que, por eso mismo, siempre es menos (respecto de eso a lo que apela). Esto equivale a sostener que para Ortega todo decir es siempre más de lo que es, más de lo que dice, y que por esta razón ningún decir, ningún texto, coincide totalmente consigo mismo. El decir raciovitalista nunca posee totalmente la verdad de sí mismo, nunca contiene en sí todo su sentido, y por ello es un decir hermenéutico, o sea, un decir que encierra en su propia constitución esencial la interpretación, un decir que es objeto necesario de interpretación.

\section{ConClusión}

A la postre, estos dos principios hermenéuticos enseñan que todo texto, decir o logos apuntan a algo más que ellos mismos, algo que es en último término indecible simbólicamente; apuntan, en suma, al horizonte siempre último de la vida humana (sea en la forma de voluntad de decir o exigencia expresiva, sea en la forma del mundo histórico-vital). En el pensamiento de Ortega todo significado se halla implantado en la vida humana, de ella obtiene su sentido, y por ello mismo se encuentra superado por el logos vital, prerreflexivo. Por eso, el texto eterno de la vida humana, como condición de posibilidad (no trascendental) y condición de inteligibilidad de los textos, como fuente inextinguible de logos, que al tiempo es inigualable por la reflexión e indecible plenamente, es el verdadero principio interpretativo radical de la filosofía raciovitalista de Ortega.

GUTIÉRREZ-POZO, Antonio. Human life as radical interpretative principle in the philosophy of Ortega y Gasset. Trans/Form/Ação, Marília, v. 35, n. 3, p. 81-96, Set./Dez., 2012.

\footnotetext{
ABSTRACT: In this article we present the concept of human life as eternal text in Ortega's thought, and its consequences for the problem of interpretation. Ortega's philosophy of vital reason is grounded in the concept of human life as radical reality and universal interpretative principle, and for this reason his philosophy appears from the beginning as a hermeneutic philosophy of life and not as reduction to transcendental consciousness. This hermeneutic is especially carried out in the sphere of art. For Ortega, however, all text is hermeneutic and therefore needs interpretation, because no text has its own truth in itself.
}

KEYWORDS: Ortega y Gasset. Human life. Interpretation. Vital reason. Text. 


\section{REFERÊNCIAS}

CASTELLÓ, J. C. La hermenéutica narrativa de Ortega y Gasset. Granada: Comares, 2009.

CEREZO, P. La voluntad de aventura. Aproximamiento crítico al pensamiento de Ortega. Barcelona: Ariel, 1984.

. De la crisis de la razón a la razón histórica. En: SAMANIEGO, M.; DEL ARCO, V. (Ed.). Historia, literatura, pensamiento. Salamanca: Narcea-Univ. de Salamanca, 1990. p. 307-344.

. La razón histórica en Ortega y Gasset. En: MATE, R. (Ed.). Filosofía de la historia. Madrid: Trotta, 1993. p. 167-191.

DOMINGO MORATALLA, T. Ortega y Gasset en la fenomenología hermenéutica. La experiencia de la traducción como paradigma hermenéutico. En: LLANO, F; CASTRO, A. (Ed.). Meditaciones sobre Ortega y Gasset. Madrid: Tébar, 2005. p. 373-410.

FLÓREZ, C. Arqueología y hermenéutica en Ortega. En: SAMANIEGO, M.; DEL ARCO, V. (Ed.). Historia, literatura, pensamiento. Salamanca: Narcea-Univ. de Salamanca, 1990. p. 439-448.

FLÓREZ, R. Historiología y hermenéutica en Ortega. Cuadernos Salmantinos de Filosofía, Salamanca, vol. XIV, pp. 69-91, 1987.

GADAMER, H-G. Sprache und Verstehen. In: Wahrheit und Methode. ErgänzungenRegister, Gesammelte Werke, Band 2. Tübingen: Mohr (Paul Siebeck), 1986a. p. 184-198.

.Was ist Wahrheit? In: Wahrheit und Methode. Ergänzungen-Register, Gesammelte Werke, Band 2. Tübingen: Mohr (Paul Siebeck), 1986b. p. 44-56.

. Grenzen der Sprache. In: Ästhetik und Poetik I, Gesammelte Werke, Band 8. Tübingen: Mohr (Paul Siebeck), 1993. p. 350-361.

HEIDEGGER, M. Der Ursprung des Kunstwerkes. In: Holzwege, Gesamtausgabe, Band 5. Frankfurt a. M.: Klostermann, 1977.

. Kant und das Problem der Metaphysik, Gesamtausgabe, Band 3. Frankfurt a. M.: Klostermann, 1991.

MOLINUEVO, J. L. Para leer a Ortega. Madrid: Alianza, 2002.

ORTEGA Y GASSET, J. Obras completas (10 vols.). Madrid: Taurus-Fundación José Ortega y Gasset, 2004-2010.

. Obras completas (12 vols.), vol. VIII. Madrid: Alianza-Revista de Occidente, 1983.

REGALADO, A. El laberinto de la razón: Ortega y Heidegger. Madrid: Alianza, 1990.

Recebido em: 20.11.2011

Aceito em: 19.02.2012 
GUTIÉRREZ-POZO, A. 